\title{
The Influences of Teacher Knowledge and Authentic Formative Assessment on Student Learning in Technology Education \\ Wendy Fox-Turnbull
}

\author{
Senior Lecturer in Technology Education and Professional Studies, Christchurch College \\ of Education, PO Box 31-065, Christchurch, New Zealand
}

\begin{abstract}
Students involved in holistic technological practice need to develop an understanding of technological practice outside the classroom and to participate in tasks set as close as practicable to actual technological practice. This paper investigates the context of assessment and its relationship to achievement and the importance of teacher knowledge to student technological practice. I argue that 'out of context' assessment tasks do not give an accurate indication of achievement levels of the children assessed. Introduced is the Model of Student Technological Practice, which identifies four constraints that influence student technological practice. A significant factor is teacher knowledge, as it impacts greatly on the quality of feedback given to students by their teachers. Timely teacher intervention and formative assessment feedback will alter student technological practice and should improve the students' likelihood of developing successful outcomes.
\end{abstract}

Key Words: technology education, authentic assessment, technological practice, student technological practice

\section{Introduction}

The quality of assessment in technology education is dependent on the quality of teacher knowledge. What to teach, how to teach and how and when to assess in technology education make up the framework for this paper. The focus for my research is the comparison of achievement levels of the children completing an assessment task that is a part of authentic technological practice to that of an 'out-of-context' task given to the children as a one off 'test-like' task. For teachers to be able to plan and implement a unit of work that is based on authentic technological practice they must have a good understanding of the conceptual, procedural, technical and societal knowledge relevant to the practice. Contextualised formative assessment within students' practice will maximise their learning.

\section{Influences on Students’ Learning in Technology Education}

Two main factors influence the quality of the achievement of children in technology education. The first factor, based on LITE Research from the University of Waikato, New Zealand (Moreland, Jones, \& Chambers, 2001), clearly indicates that teacher understanding of technology and teacher knowledge of the relevant technological practice engaged by the students influences the quality of learning that occurs for the students. Teachers must 
therefore develop and assess quality learning based on a thorough knowledge of the relevant technological practice.

The second factor is the relevance or authenticity of the task in relationship to the children. Technology in the New Zealand Curriculum (Ministry of Education, 1995) states clearly, in several places, that technology education for students needs to be authentic. Hennessy and Murphy (1999) discuss the possibility that authentic practice actually happens at two levels. "Real" to the students may be real to their own lives or real to situations that they may encounter in the future workplace. The second level is real to technological practice, reflecting the practice of practitioners as much as is practicable in the classroom situation. "Activity is said to be authentic if it is (i) coherent and personally meaningful and (ii) purposeful within a social framework - the ordinary practices of culture” (Hennessy \& Murphy, 1999, p. 8). An important message about the nature of activities that children undertake is that authentic learning engages children and encourages learning (Hennessy \& Murphy, 1999; Hill \& Smith, 1998; Rogoff, 1990).

Shulman (1987, cited in Jones and Moreland, 2001) suggests an emphasis is needed to develop a strong teacher knowledge base in the areas of content knowledge, general pedagogy, curriculum, pedagogy content, learners' educational context, and educational ends. Moreland, Jones and Chambers (2000) identify that effective teaching and assessment in technology is positively influenced by the development of a knowledge base in four domains: procedural, conceptual, societal and technical. More recent research has focused on the classroom delivery and assessment of technology. The LITE research (Moreland et al., 2001) was pivotal in developing understanding of the necessity for teachers to have specific knowledge within the identified technological practice and how this is used to plan, implement and assess quality programmes of work in technology education. Formative interactions with students become distorted if there is a lack of subject knowledge and its construction.

\section{Authentic and Formative Assessment}

Authentic assessment opportunity is an assessment opportunity that is a part of a student's identified technological practice. Technology in the New Zealand Curriculum states:

Assessment of technology education is more than the assessment of the individual components: rather the whole task or outcome should be evaluated. Emphasis on a narrow component or testing outside the context of learning does not enable reliable judgments to be made. Nor do single-focus 
standard assessment tasks, designed to rank or assess students in relation to levels, meet the purpose outlined above (Ministry of Education, 1995, p. 24).

To understand the place of assessment within technological practice we must also define technological practice. One useful model is Gawith's (2000) model of technology practice (Figure 1), which situates the technologist or technology team within the purposeful action of technological development. There are clear links between this model and Technology in the New Zealand Curriculum. Three stands (A, B and C) are incorporated into the aim of technology education in New Zealand (Ministry of Education, 1995). Gawith’s model (Figure 1) offers a holistic approach to technological practice. He indicates that all technological practice takes place within a social context. The definition for Strand C, Technology and Society, states "Technological practice takes place in and is influenced by, social contexts" (Ministry of Education, 1995, p. 6). Knowledge of existing organisation, information and resources has close links to Strand A, Knowledge and Understanding. Skills and techniques are a part of the development of safe practice in Strand B, Technological Capability.

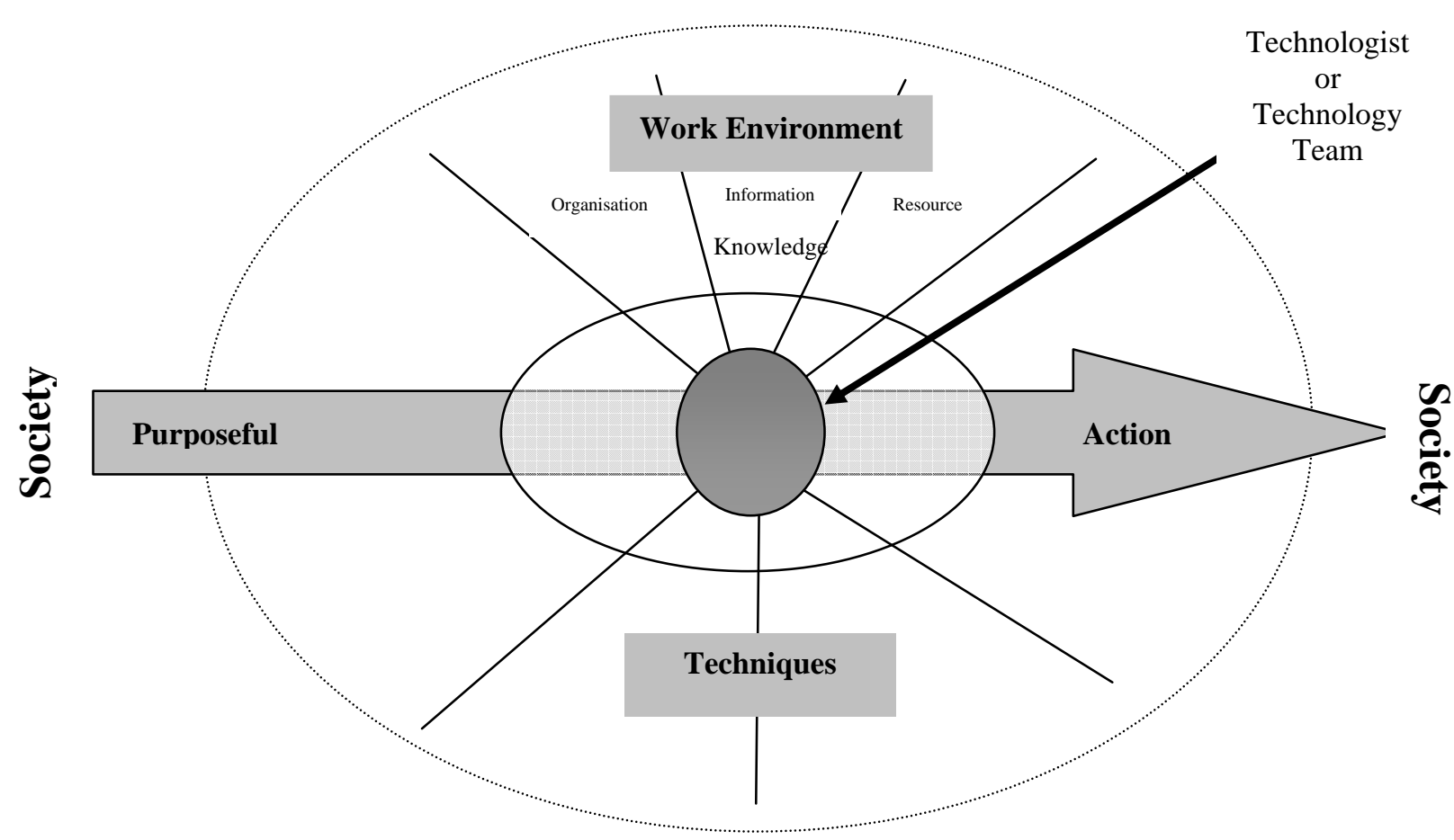

Figure 1: Gawith's (2000) model of technology practice

This model encompasses the underlying theoretical philosophy of Technology in the New Zealand Curriculum that student technological practice is holistic, reflecting authentic technological practice within the learner's possible current or future field of knowledge. 
Wiggins (1998) suggests that authentic tasks are realistic when they replicate the ways in which knowledge and abilities are 'tested' in the real world. I acknowledge that total authenticity is not always practical, especially in a primary classroom (Turnbull, 2002). Children do not have the skills, equipment or understanding to be completely authentic, but their processes should be able to reflect authentic practice even if the content of the processes used differs. The use of plastic is an example where children may be unable to produce an injection-moulded plastic product. They might still be able to make a model of their outcome in another plastic-coreflute and then recognise that the final outcome may in fact need to be injection moulded. Despite this difference, the initial research, designing and modelling process can be very similar to actual technological practice. At times in the classroom there will be aspects of practice the children are unable to do because of safety. This work can be given to experts to do. For example, children can design and paint puzzles onto plywood, but may use an expert to saw the puzzles into pieces. Children are still making decisions and have control over their designs - for example where the cuts will occur. In actual fact, in 'real' practice, many technologists get other experts to do highly specialised aspects of their practice. It is logical to conclude that in order to plan a quality unit of work in technology teachers must have a sound knowledge of the relevant technological practice.

The aim of assessment is to educate and improve student performance and teaching (Freeman, 1998; McGee \& Fraser, 2001; Wiggins, 1998). Assessment should be designed to teach, not just to measure, by revealing to the students what worthy adult work looks like (authentic tasks) (Wiggins, 1998). This type of assessment is called formative assessment. Formative assessment is developed from a notion that assessment should be on-going and used through a middle period of child-centred activities rather than at the end of a unit or at the end of the year (summative assessment) (Black \& Wiliam, 1998; Clarke, Hattie, \& Timperley, 2003). The aim of formative assessment is to provide feedback to students and allow teachers to modify learning activities to meet students’ emerging needs (Black \& Wiliam, 1998).

Formative assessment must be overt to students, offering clearly stated criteria, which are known to the students and their teachers. It should also provide rich, useful feedback to the students and their teachers. Feedback needs to be timely and ongoing (Clarke et al., 2003; Compton \& Harwood 1999; Sutton, 1995; Wiggins, 1998).

The reasons that assessment must be anchored in and focused on authentic tasks is because they supply valid direction, intellectual coherence, and motivation for the day-in day-out work of knowledge and skill development. (Wiggins, 1998, p. 21) 
Kimbell (1997) very neatly identifies one of the key issues of assessment in technology education. Fundamental to technology education worldwide is the process of design and development rather than a body of knowledge and skills as in other curriculum areas. Practical knowledge and skills enhance this process but assessment of students' ability to design and develop solutions to meet identified needs is much more complex than the assessment of their knowledge and skills. Technology education is leading the field in process-based assessment. Formative assessment fits comfortably within this model.

\section{Method}

This study used the same assessment task in two different ways with selected children from the same six classes of Year 4 children. Initially, the task was used as an 'out-of-context' assessment task. This meant that the children were asked to complete the task before being involved in any study of the relevant technological practice. This is the manner in which technology is assessed by the National Education Monitoring Project (NEMP) in New Zealand.

NEMP (Crooks \& Flockton, 2001) commenced in New Zealand in 1993 to assess and report on achievement of primary school- age children. The focus of NEMP is on the educational achievement and attitudes of New Zealand primary and intermediate school children (Crooks \& Flockton 2001). Years 4 and 8 (8-9 and 11-13 years of age) children are assessed in all curriculum areas over a four-year cycle. Technology was first assessed in 1996 and 'Aspects of Technology' were assessed in 2000 (Crooks \& Flockton, 2001). For this project I used a task selected from Aspects of Technology 2000.

The same task was later used embedded within a unit of work that reflected the relevant authentic technological practice as closely as is practical in the primary classroom (the 'incontext' task). The unit of work was cooperatively planned by the six classroom teachers and myself and was based on developing procedural, conceptual, societal and technical knowledge of the relevant technological practice.

\section{The Task for this Study}

The task 'Help Me Peel' required the children to prepare and annotate a plan of an aid to help a one-handed person peel a potato. They were also required to explain how their design worked. Figure 2 provides a copy of the instruction card and photograph given to the children as a part of their task. 

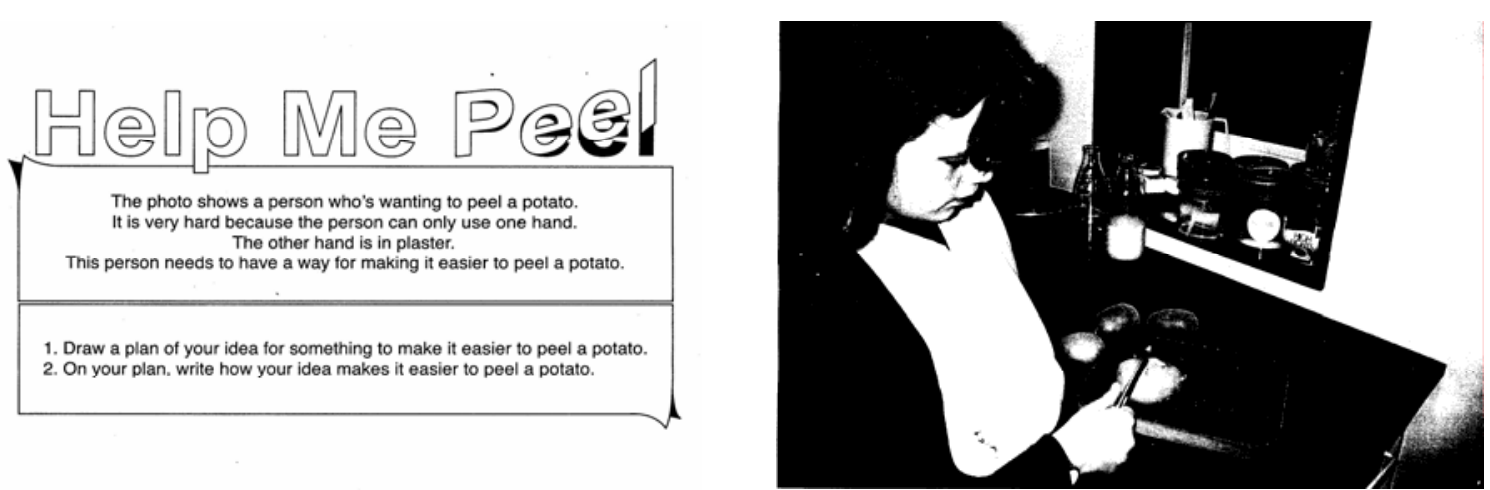

Figure 2: Help Me Peel task and photo provided for this study by NEMP.

\section{School Selection}

I restricted the population to all primary schools in greater Christchurch, New Zealand and then sent a letter requesting participation to the principals of these schools. I selected the schools by taking the first two schools that agreed to participate in each of the three socioeconomic (SES) bands by which the Ministry of Education in New Zealand categorizes schools and bases funding and support. The NEMP 2000 results indicate that a school's SES index influences results (Crooks \& Flockton, 2001). These findings from NEMP justified the use of stratified sampling.

For the study I split the schools into two groups (see Table 1). Half the schools, one from each SES group, did not experience the task as an 'out-of-context' task. These schools were Group Two schools and formed a control, as they did not have exposure to the task twice. For the Group One schools (those remaining), the task was administered to six children in each class as an 'out-of context' task before the unit was taught. There were 17 children in the 'out-ofcontext' task group and 36 children in the 'in-context' group.

Table 1: The relationship of schools in the research group to decile band and task administered

\begin{tabular}{|lcc|}
\hline Class & Out-of-context & In-context \\
\hline $1 \quad$ (SES 8-10) & \\
School A Group 1 & $\checkmark$ & $\checkmark$ \\
\hline $2 \quad$ (SES 8-10) & & $\checkmark$ \\
School B Group 2 & & \\
\hline $\begin{array}{l}\text { 3 SES 4-7) } \\
\text { School C Group 1 }\end{array}$ & $\checkmark$ & $\checkmark$ \\
\hline $\begin{array}{l}4 \quad \text { (SES 4-7) } \\
\text { School D Group 2 }\end{array}$ & & $\checkmark$ \\
\hline $\begin{array}{l}\text { 5 (SES 1-3) } \\
\text { School E Group 1 }\end{array}$ & $\checkmark$ & $\checkmark$ \\
\hline $\begin{array}{l}\text { 6 (SES 1-3) } \\
\text { School F Group 2 }\end{array}$ & \\
\hline
\end{tabular}




\section{The Help Me Peel Unit}

During the unit the children participated in a series of activities or learning experiences that reflected research and activities that could be undertaken in the real practice of a person developing aids for people with disabilities. These included such things as peeling vegetables, listening to an arm amputee talk about the challenges and frustrations of having one arm, discussion about who has one arm and why, investigating existing aids on the market and investigating a range of possible suitable materials for aids. Before planning their aid, the children identified necessary and desirable criteria for it. These included keeping the potato secure, keeping the aid still, easy to clean and easy to put away. To develop these criteria, the children needed to recall learning from preceding learning. The children sketched two or three initial ideas on draft paper and selected one they intended to make and then wrote and verbally justified their selection to a teacher or a group of peers. They then took their selected idea and developed it fully into an annotated plan of aid, including annotations about size, materials used and an explanation as to how their designs would make it easier to peel potatoes. At this stage, selected children had their plans and explanations assessed using the same criteria as the 'out-of-context' task. The children then made a cardboard mock-up, evaluated their designs and finally constructed and tested their aid.

\section{Assessment of the Task}

The achievement levels of children for the 'out-of-context' and 'in-context' task were compared and contrasted to allow me to ascertain whether the achievement levels of the selected children were better when the task was used as a formative assessment task ('incontext'). Changes in achievement levels between the 'out-of-context' and 'in-context' task give insight into the effectiveness of students' teaching and learning.

Tasks were analysed using the aspects and categories determined by NEMP and the subcategories determined by me to ensure consistency across all the data (Tables 2-5). Both tasks were analysed after the unit was taught. This ensured that the information gained did not influence the approach taken to unit planning and teaching. Detailed analysis served to indicate the effectiveness of teaching and how the improved teacher knowledge and practice improved student achievement. 


\section{Marking Criteria}

To ensure that the tasks were assessed consistently, I requested and adapted the marking aspects and categories for this task used by NEMP in 2000. NEMP had assessed five aspects:

1 A second person is required

2 Quality of the solution

3 Quality of plan/ diagram/ picture independent of its workability

4 Quality of explanation

$5 \quad$ Nature of the solution.

I used aspects 2-5. Aspect 1 was not used because at the suggestion of NEMP personnel I gave the children an added instruction which made it inapplicable. Within each aspect identified three or four assessment categories were also determined. Both the aspects and the categories provided by NEMP appear in italics in Tables 2-5. The point values allocated to each category by NEMP are also in these tables. This determination allowed a numerical score to be calculated for each child.

When NEMP assessors mark the NEMP tasks, there are a large number of markers who discuss, compare and moderate their findings to ensure consistency of standards. To ensure consistency in this project with only one marker, I decided I needed further categories or subcategories within each of the categories. These can also be seen in Tables 2-5, as bullet points below each category.

Another modification I made was to the NEMP categories in the fifth aspect, 'Nature of the solution'. I added another category that I believed to be of equal rating to that of holding the potato still and this was 'Allows for the aid to be held still or stabilised'. I came to this decision through research into existing aids currently on the market for one-handed people and discussion with Vaughan Hill (the video interviewee). Vaughan talked about the importance of the aid not slipping and sliding across the table or bench when it is used. I believe that the children needed to be given credit if they recognised this aspect and had included it in their design. I gave it an equal weighting as 'holds the potato still' because holding the potato still may not be effective if the aid slips away from the peeler.

In Tables 2-5 the aspects and categories determined by NEMP and the points allocated to each are in the top row. In the second row are the sub-categories that I identified as key 
components for each of the given categories. The most desirable criteria are on the left and least desirable on the right for each aspect.

Table 2: Aspect 1 - Quality of the Idea/ Solution- Its workability

\begin{tabular}{|c|c|c|c|}
\hline $\begin{array}{l}\text { Clearly Workable } \\
3 \\
\end{array}$ & $\begin{array}{l}\text { Probably workable } \\
2 \\
\end{array}$ & $\begin{array}{l}\text { Possibly Workable } \\
1 \\
\end{array}$ & $\begin{array}{l}\text { No Solution/ unworkable } \\
\text { solution } \\
0 \\
\end{array}$ \\
\hline $\begin{array}{l}\text { - Able to keep potato still- } \\
\text { e.g. cup, two nails/sticks } \\
\text { - Able to be held secure on } \\
\text { the bench-plastic matting } \\
\text { or suction cups } \\
\text { - Appropriate size and } \\
\text { materials } \\
\text { - Can be used by a one- } \\
\text { handed person }\end{array}$ & $\begin{array}{l}\text { - May keep potato still-, } \\
\text { one nail/stick } \\
\text { - Aid may be held secure } \\
\text { on the bench } \\
\text { - Size and materials not } \\
\text { clearly stated } \\
\text { - May be able to be used } \\
\text { by a one-handed person }\end{array}$ & $\begin{array}{l}\text { Keeping the potato } \\
\text { still considered but } \\
\text { probably won't do it } \\
\text { - } \quad \text { No way to secure aid } \\
\text { to bench } \\
\text { - } \quad \text { Size not considered } \\
\text { - } \quad \text { Materials not } \\
\text { considered } \\
\text { - }\end{array}$ & $\begin{array}{l}\text { - Won't keep the potato still } \\
\text { - Can't be secured to bench } \\
\text { - May be futuristic and little } \\
\text { likelihood of being able to } \\
\text { be produced now or in the } \\
\text { future } \\
\text { - No solution offered }\end{array}$ \\
\hline
\end{tabular}

Table 3: Aspect 2 - Quality of the Plan-Independent of its Workability

\begin{tabular}{|l|l|l|}
\hline Quite detailed & Rudimentary & $\begin{array}{l}\text { No plan/diagram/ picture. Scored } \\
\text { if there is no plan/ picture/ diagram } \\
\text { offered } \\
0\end{array}$ \\
\hline $\begin{array}{l}\text { - May offer two views } \\
\text { - Measurements given }\end{array}$ & 1 & $\bullet$ No solution offered \\
\hline
\end{tabular}

Table 4: Aspect 3 - Quality of the Explanation-Independent of its Workability

\begin{tabular}{|c|c|c|}
\hline $\begin{array}{l}\text { Quite detailed } \\
2\end{array}$ & $\begin{array}{l}\text { Rudimentary } \\
1\end{array}$ & $\begin{array}{l}\text { No Explanation } \\
\text { Scored if there is no explanation } \\
\quad 0\end{array}$ \\
\hline $\begin{array}{l}\text { - Discusses how it will make } \\
\text { it easier to peel the potato } \\
\text { - Explanation expands on } \\
\text { information given in the } \\
\text { diagram/picture }\end{array}$ & $\begin{array}{l}\text { - Discusses the picture but gives } \\
\text { little or no relevant information } \\
\text { on their design }\end{array}$ & - No explanation offered \\
\hline
\end{tabular}

\section{Table 5 Aspect 4 - Nature of the Solution}

\begin{tabular}{|c|c|c|c|c|c|}
\hline $\begin{array}{l}\text { Ways of holding } \\
\text { potato still (so can be } \\
\text { operated with a single } \\
\text { hand) } \\
\quad 5 \\
\end{array}$ & $\begin{array}{l}\text { Ways of holding aid } \\
\text { still (so can be } \\
\text { operated with a single } \\
\text { hand) } \\
\quad 5 \\
\end{array}$ & $\begin{array}{l}\text { Ways of holding peeler } \\
\text { still (so can be operated } \\
\text { with a single hand) } \\
\quad 4\end{array}$ & $\begin{array}{l}\text { Machine } \\
\\
3 \\
\end{array}$ & $\begin{array}{l}\text { Getting somebody else } \\
\text { to help by holding (so } \\
\text { you can peel potato } \\
\text { with a single hand) } \\
\quad 2 \\
\end{array}$ & $\begin{array}{l}\text { No Workable } \\
\text { Solution/ any } \\
\text { other response } \\
\qquad \begin{array}{l}0 \\
\end{array}\end{array}$ \\
\hline $\begin{array}{l}\text { Will offer at least one } \\
\text { of the following: nails } \\
\text { at least two, split pins } \\
\text { or skewers, cup } \\
\text { formation, holes or } \\
\text { wedge for the potato }\end{array}$ & $\begin{array}{l}\text { Will have at least one } \\
\text { of the following: } \\
\text { matting on the } \\
\text { bottom, } \\
\text { suction pads on the } \\
\text { bottom, clamp to } \\
\text { attach to bench or } \\
\text { table, method of } \\
\text { trapping the device }\end{array}$ & $\begin{array}{l}\text { A device that holds the } \\
\text { peeler still so the potato } \\
\text { can moved against the } \\
\text { blade. Must mention the } \\
\text { moving of the potato } \\
\text { against the blade }\end{array}$ & $\begin{array}{l}\text { Will use } \\
\text { electricity } \\
\text { May have a } \\
\text { motor } \\
\text { Possibly be } \\
\text { futuristic }\end{array}$ & $\begin{array}{l}\text { Will involve another } \\
\text { hand or other hands in } \\
\text { the operation }\end{array}$ & $\begin{array}{l}\text { Solution unable } \\
\text { to be made and or } \\
\text { unrealistic for the } \\
\text { intended purpose }\end{array}$ \\
\hline
\end{tabular}


Total scores were calculated for each child in each task. This allowed me to identify low and high scoring plans for both tasks. Six children were coincidentally selected for both the 'outof-context' and the 'in-context' task and therefore received a score for both.

\section{Results}

For each criterion I compared the 'out-of-context' task with the 'in-context' task. There were no significant differences in the results between decile bands and therefore this is not reported in this article.

Table 6: Quality of the Idea/ Solution; the results of the out-of-context and in-context task in percentage of children who scored in each criterion

\begin{tabular}{|l|c|c|c|c|}
\hline Criteria & $\begin{array}{l}\text { Clearly } \\
\text { Workable }\end{array}$ & $\begin{array}{l}\text { Probably } \\
\text { Workable }\end{array}$ & $\begin{array}{l}\text { Possibly } \\
\text { Workable }\end{array}$ & Not Workable \\
\hline Out-of-context & $\mathbf{1 8}$ & $\mathbf{6}$ & $\mathbf{2 9}$ & $\mathbf{4 7}$ \\
\hline In-context & $\mathbf{6 7}$ & $\mathbf{2 2}$ & $\mathbf{8}$ & $\mathbf{3}$ \\
\hline
\end{tabular}

There is a big shift here between the 'out-of-context' task and the 'in-context' task. Almost half (47\%) of the children in the 'out-of-context' task presented a solution that was unworkable and $67 \%$ of children in the 'in-context' task produced a clearly workable solution. During the teaching in the unit the children were exposed to a number of different aids that one handed people use. The amputee shared a number of aids he uses to help complete everyday tasks. Another activity the children were required to do was to look at pictures of a number of aids supplied by Enable New Zealand. The realisation that there are people out in the real world who actually require aids to help them do everyday tasks and that aids are actually made for these people had an impact on the solutions offered by the children. By making use of a deliberate social context (Hennessy, 1993) the activity became more relevant and meaningful as the children realised that anyone could become one-handed at any time and that people do actually design aids to help one-handed people. This highlights the need for recognition that technology is socially constructed and has huge consequences for quality of life for some people. Research and knowledge of practice by the teachers allowed the students to be exposed to activities to increase their awareness of aids for people with disabilities. On-going formative assessment allowed teachers to monitor the nature of the students' understanding.

Table 7: Quality of the Plan, the results of the out-of-context and in-context task in percentage of children who scored in each criterion

\begin{tabular}{|l|c|c|c|}
\hline Criteria & Detailed & Rudimentary & $\begin{array}{l}\text { No Solution/ Plan/ } \\
\text { Explanation }\end{array}$ \\
\hline Out-of-context & $\mathbf{0}$ & $\mathbf{1 0 0}$ & $\mathbf{0}$ \\
\hline In-context & $\mathbf{6 7}$ & $\mathbf{3 3}$ & $\mathbf{0}$ \\
\hline
\end{tabular}


These results could be explained in several ways. Detailed plans were required to list measurements or note the materials used in the design. One of the unit activities was an investigation into a range of materials. The children scrubbed, folded, slid across a bench and tore selected materials to test them for desirability. Each group concluded the activity by listing the materials that may be suitable for their design. Children also sketched three initial design ideas and discussed these with their peers or an adult so that by the time they planned the 'in-context' task they had sketched and verbalised ideas and selected a final idea based on the feedback they received. Procedural knowledge (McCormick, 1997) could explain the increased achievement. The children were aware that their plans were to help them move through the design process of developing an aid. McCormick (1997) identified that procedural knowledge is a major component in successful learning in technology.

Formative assessment of students' planning allows teachers insight into the way children have used information from prior learning and teacher planned learning experiences. It is very important that teachers allow children the opportunity to discuss their planning and justify their decision making. New and complex thinking and understanding are not always obvious from just looking at the children's work. Allowing children the opportunity to discuss their work not only aids their development and learning but gives teachers valuable insight into children's thinking. Teachers can also use this as an opportunity to give feedback to the students regarding the quality, usefulness or practicality of their designs by asking questions to extend children's thinking. How well teachers do this will depend on a number of things including their knowledge of the technological practice.

Table 8: Quality of the explanation, the results of the out-of-context and in-context task in percentage of children who scored in each criterion.

\begin{tabular}{|l|c|c|c|}
\hline Criteria & Detailed & Rudimentary & No Explanation \\
\hline Out-of-context & $\mathbf{1 8}$ & $\mathbf{8 2}$ & $\mathbf{0}$ \\
\hline In-context & $\mathbf{7 5}$ & $\mathbf{2 5}$ & $\mathbf{0}$ \\
\hline
\end{tabular}

To obtain a 'detailed' explanation the children needed to expand on the information given on their plan and discuss how the design would achieve its required purpose. By having completed the unit activities the children completing the 'in-context' task were more confident justifying their decision making. Identification of the criteria needed for a successful aid (such as: needs to be washable; needs to keep the potato still; aid needs to be stable; etc.) is clearly reflected in the children's explanations in the 'in-context' task (spelling edited by the researcher where necessary).

It holds the potato by wedging it in (Billy, School C) 
It makes it easier because the potato doesn't move and the board (doesn't move). (Oshiarne, School E)

It makes it easier to peel the potato because the potato stays still in the hole and the suction pad keeps the wood still. The Vivac keeps the aid clean while not used. The aid can be cleaned with water. You can put it away. (Laura, School A).

It is clear that the children were aware of the need to secure the potato and stabilise the actual aid. The amputee mentioned these things in the video and many of the aids in the pictures the children saw also had these features.

\section{Table 9: The Nature of the Solution, the results of the out-of-context and in-context task in percentage of children who scored in each criterion.}

\begin{tabular}{|l|c|c|c|c|c|c|}
\hline Criteria & $\begin{array}{c}\text { Holds } \\
\text { Potato still }\end{array}$ & $\begin{array}{c}\text { Holds aid } \\
\text { still }\end{array}$ & $\begin{array}{c}\text { Holds } \\
\text { Peeler still }\end{array}$ & Machine & $\begin{array}{c}\text { Person } \\
\text { Helping }\end{array}$ & No solution \\
\hline $\begin{array}{l}\text { Out-of- } \\
\text { context }\end{array}$ & $\mathbf{3 3}$ & $\mathbf{1 2}$ & $\mathbf{0}$ & $\mathbf{1 8}$ & $\mathbf{6}$ & 47 \\
\hline In-context & $\mathbf{8 6}$ & $\mathbf{6 9}$ & $\mathbf{3}$ & $\mathbf{3}$ & $\mathbf{0}$ & 3 \\
\hline
\end{tabular}

In this aspect unlike any of the others the children were able to score in more than one category. The learning experiences modeled in authentic technological practice that took place between the 'out-of-context' task and the 'in-context' task allowed the children to improve achievement in planning technological solutions to meet identified needs. Constructivist theory describes how knowledge frameworks are built up, tested and altered as new knowledge comes to light. Children are motivated when they can see the relevance of and/or a need for their solution (Hennessy \& Murphy, 1999; Hill \& Smith, 1998). The clear differences between the nature of the solution in the 'out-of-context' task and the 'in-context' task indicate that these children built frameworks constructed during their authentic practice which enhanced their achievement.

One way of illustrating the difference authentic technological practice makes is by comparing high scoring plans in the 'out-of-context' task with high scoring plans in the 'in-context' task. The high scoring plans in the 'out-of-context' task met the criteria just as those in the 'incontext' task. By comparing the two we are able to see a shift in thinking related the practicality of the designs and the quality and clarity of ideas presented by the children. Figure 4 shows a design that scored highly in the 'out-of-context' task. On the right is a copy of Anna's work and on the left comments show the relationship between the criteria and Anna’s design. 


\section{Quality of the Solution}

Design is probably workable

Keeps the potato still

Not secured to bench

Size and materials notstated

Could be used by a one handed persor

Quality of the Plan

Quality of plan rudimentary

No annotation

Very small

Basic picture

Quality of the Explanation

Quality of explanation quite detailed

Discusses how it will make peeling a potato easier.

Expands on information portrayed in the picture

Read the instruction card and draw your plan here.

My Plan

way to make it easier to peel a potato using only one hand.

then you wind or

When you wynd of

the narde the to the

in closerveu could

wynd the handle in to the size of the potata and make

the two meat walls come in

nice and tyte you can peel

the potato as much as you

can and keep turing the
potato around.

Figure 4: High Scored Plan from the Out-of-context Task: Anna, School A

The design shows that Anna has an understanding that the potato needs to be secured. The idea represented here is similar to that of a vice used for securing objects in a workshop. Anna must have used existing knowledge about keeping objects still.

Figure 5 shows a copy of Mathew's high scoring plan from the 'in-context' task. On the left is a copy of Matthew's plan and explanation. On the right are the comments to link Matthew's performance to the assessment criteria. Matthew has given careful consideration to securing the aid, securing the potato, dimensions and the materials used. His design has met several of the criteria for the aid determined by the children as a part of their technological practice. 


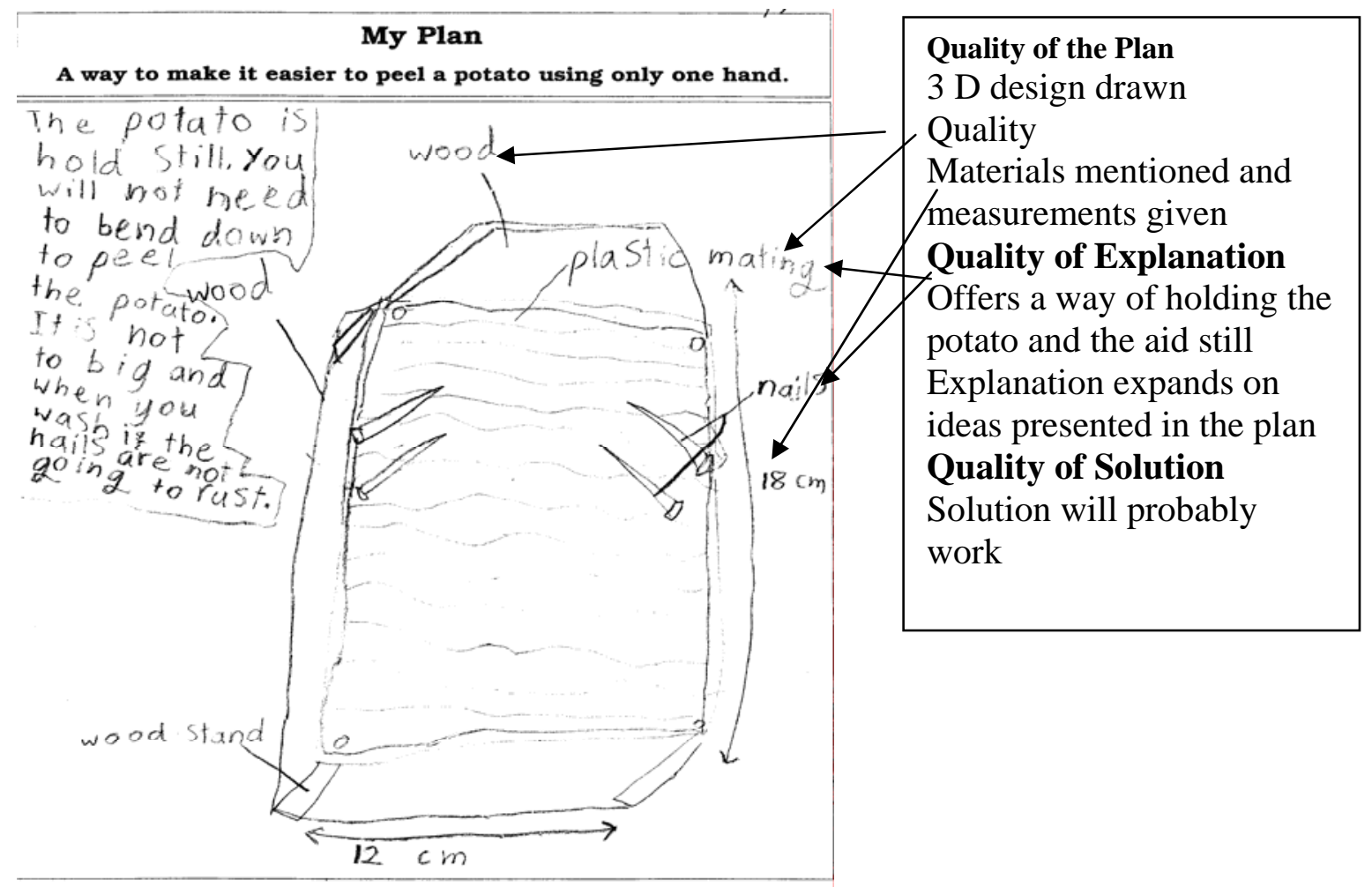

Figure 5: High Scoring Plan from the In-context Task, Matthew, School D

This point is further illustrated by Brittany, School A, was selected to do the task both times.

She scored maximum points for the 'Quality of the Solution' aspect in both the 'out-ofcontext' task and the 'in-context' task. By comparing the two we are able to see the influence her technological practice had on her ability to design a suitable practical solution to the identified problem.

Figure 6 : On the left is Brittany's out-of-context task and on the right is her in-context task.

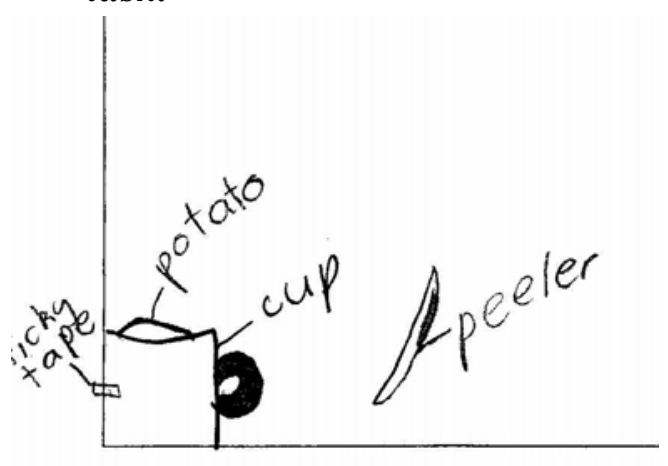

YEAR 4:2000

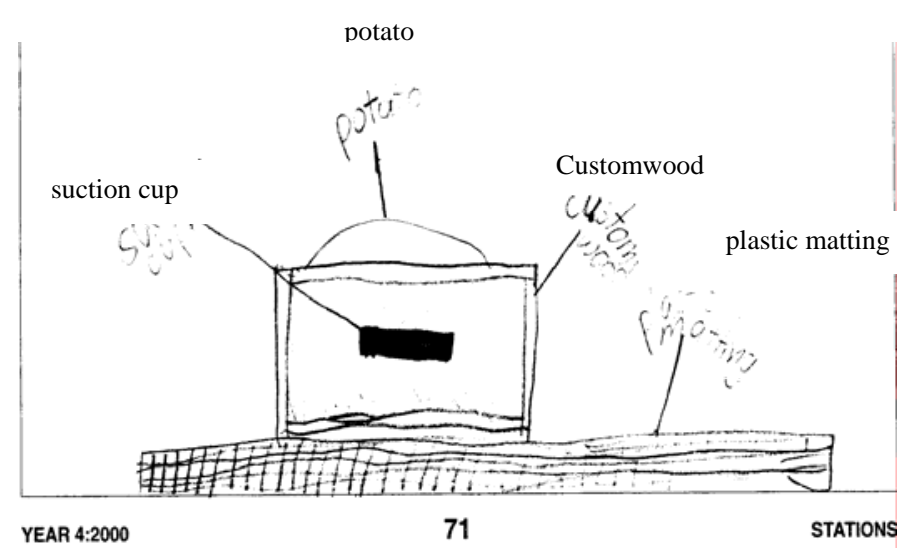

YEAR 4:2000
71

Her 'out-of-context' plan shows a cup stuck to the wall. The high score in this aspect is attributed to the fact that the plan mentions holding the potato and the aid still. Brittany was the top scorer in the 'out-of-context' task. It is clear her solution shows insight into the 
requirements needed to peel a potato one-handed but she appears not to have had the knowledge or experience to plan a more practical solution e.g. suction cups rather than sticking tape to secure the aid to the wall. There are a number of features of Brittany's design that are common to both her plans. These include having the potato sitting within walls and securing the aid to the wall. Brittany's 'in-context' task is much more practical than the 'outof-context' task and met all the criteria determined by the children in her class. This indicates improved understanding of the requirements a technological solution of this nature requires.

\section{Discussion}

When teachers have a deeper understanding of the knowledge necessary for technological practice they are better equipped to direct students along a pathway to developing successful technological processes or outcomes by planning relevant activities within their units (Moreland et al., 2001). Jones and Moreland (2001) found that working across all four knowledge domains enhanced children's learning. Technology in the New Zealand Curriculum suggests that in most cases all three strands be taught within each unit (Ministry of Education, 1995).

By giving these children an authentic problem increased their motivation significantly. In all aspects assessed the children from the 'in-context' task performed considerably better than those doing the 'out-of-context' task. The children's achievement in the 'in-context' task was enhanced by the technological practice that preceded it. This practice involved learning in all four domains (Jones \& Moreland, 2001) and in all three strands of Technology in the New Zealand Curriculum (Ministry of Education, 1995). The paragraphs below show the relationship between the activities the children did and the knowledge domains and strands.

Procedural Knowledge: Knowing the procedure of peeling a potato was critical to the children's understanding of the requirements of an aid. While peeling they needed to think about what the hand without the peeler was doing. This helped them to identify what an aid might need to do. They needed to be able to examine a series of pictures of aids for onehanded people (technologies in the field) and identify key features. Once again this process was fundamental to building up an understanding of aids for one-handed people (Strand A and B learning experiences).

Conceptual Knowledge: Conceptual knowledge was also vital to practice (McCormick, 1997). The children learnt that aids increase stability of the object and that the aids themselves are 
not as effective if they slide around the bench. The learning experiences allowed them to discover that spikes, wedging, suction, and increased friction are used for increasing stability (Strand A learning experiences).

Societal Knowledge: Societal knowledge had a big impact on these children. Viewing the video allowed them to see a man whose life was shattered by losing one arm. The children's empathy to the amputee amazed me. We also discussed why people may only have the use of one arm. One girl told me she was going to give her aid to her aunty because she (the aunt) had lost her arm to cancer. Hennessy \& Murphy, (1999) and Hill \& Smith (1998) discuss that an individual's ability to construct representations within frameworks increases knowledge (Strand C learning experiences).

Technical Knowledge: Technical skills such as peeling carrots and potatoes and using a hot glue gun safely were taught (Strand A and B learning experiences).

I acknowledge that these tasks offer only a snapshot of authentic technological practice but they helped the children realise that the need identified in the picture was authentic and that there are people in our community who either design and/or use such aids. Brown et al. (1989) discuss in the theory of enculturation the influence of culture on practice and also identify a difference between much school activity and authentic activity. It is the responsibility of educators in technology and narrow this difference as much as possible. I argue that the development of improved teacher knowledge and awareness of technological practice enables teachers to plan units of work that are based on authentic practice. It will also enable teachers to plan quality formative assessment opportunities and give students feedback based on authentic practice, aimed at improving student performance.

\section{Model of Student Technological Practice}

The Model of Student Technological Practice (Figure 7) introduced in this paper illustrates how teacher knowledge and formative assessment alter student technological practice. The model is an extension of authentic technological practice based on Gawith's(2000) and to a lesser degree Pacey's (1983) earlier model. Student technological practice should mirror authentic technological practice. In reality however, exact replication is not possible. There are constraints within which teachers have to work; these are illustrated in figure 7 as a frame within which student technological practice occurs. 


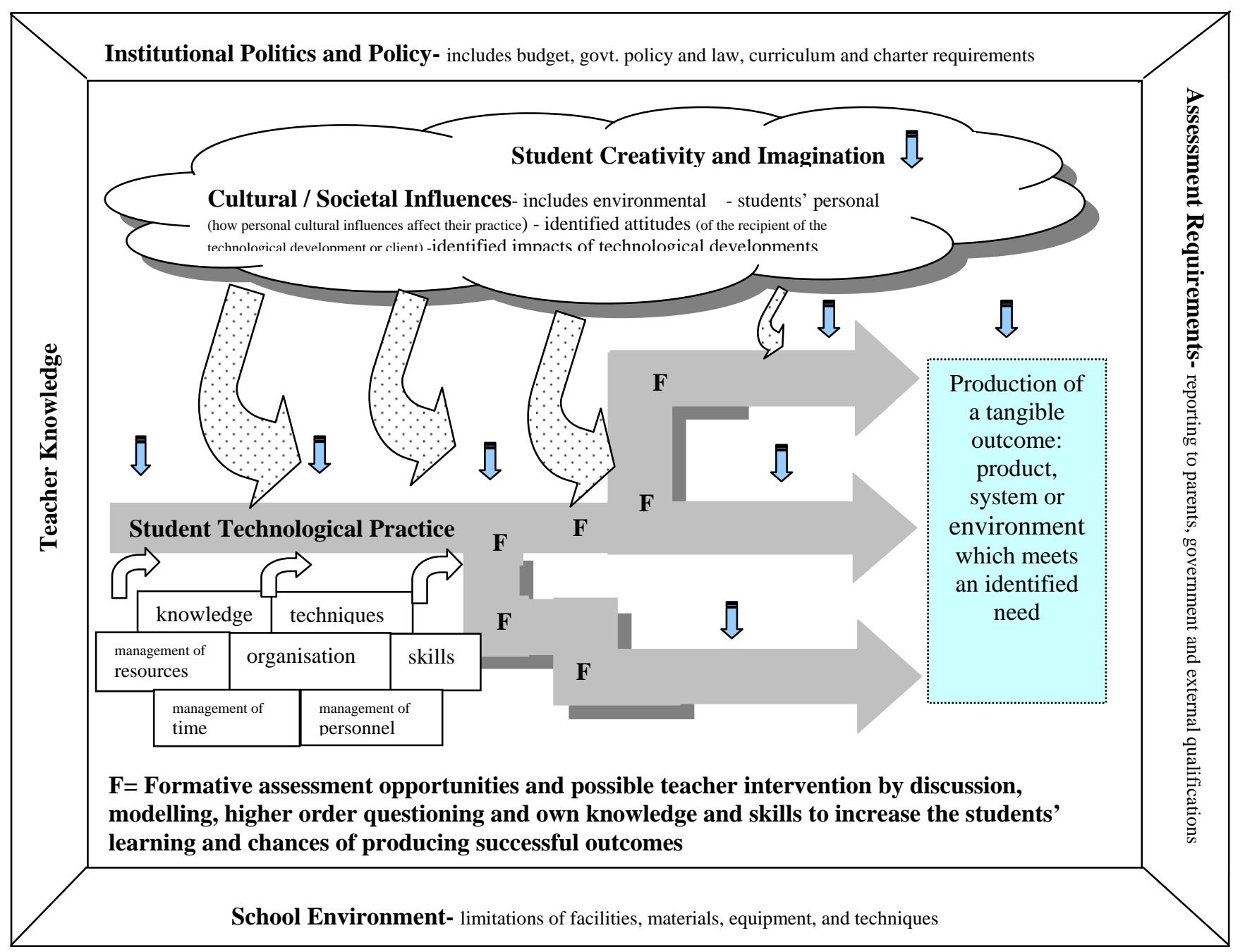

Figure 7 Model of Student Technological Practice

The first of these constraints is Institutional Politics and Policy. This influences classroom practice by imposing requirements on the teachers and students. These include such things as curriculum considerations, school charters and policy, timetables and budget constraints. The second factor is the School Environment. The nature of the facilities available in schools will limit processes available to the students and therefore affect student technological practice. It is neither practical nor feasible for schools to have very expensive and complex facilities, machines or equipment to allow students to undertake specialised technological practice. There are many procedures that students are not physically capable of doing safely. As a part of authentic student practice however, students should be able to recognise which process could be best used to produce the final outcome. The third factor is Teacher Knowledge. To allow students to mirror technological practice teachers need to be aware of the knowledge and skills needed by technologists in the field of practice being studied. They also need to be aware of the logical sequences of the learning. When planning learning experiences teachers need to take these into account allowing children to experience practice that is as authentic as 
possible. Teacher knowledge is critical here. Without sound knowledge teachers are unable to plan logical, relevant sequenced activities. It will also affect the quality of guidance given to their students. Moreland et al. (2001) state that teacher content and pedagogical knowledge is pivotal for effective technology teaching. The fourth factor is Assessment Requirements. It has long been known that external assessment requirements influence classroom practice. In New Zealand, Technology Education has been included in the new National Certificate in Education Achievement (NCEA) implemented at Level One in 2002, Level Two in 2003 and Level Three in 2004 for secondary students in Years 11-13 (15-18 years of age). It is inevitable that the structure of the qualification will influence the practice of students and teachers.

The centre of the model shows technological practice for students in a similar fashion to that of Gawith (Figure 2). It acknowledges that social and cultural values and beliefs and creativity and imagination influence all technological practice. It also suggests that existing knowledge, skills and techniques along with management of resources personnel and time are inputs into technological practice. However unlike real technological practice teacher intervention in the form of formative assessment occurs. Failure and failure analysis are a very important part of the technological process. Teachers should allow students to make and learn from their mistakes. As students become aware of new learning the likelihood of producing a successful outcome increases. Figure 7 shows how students' practice can be altered by teacher intervention through formative assessment opportunities by using open ended or higher level questions to extend and challenge students thinking, suggesting techniques and ultimately affecting student practice. Teachers need to catch the 'teachable moment' to maximise learning. Too much teacher intervention or inappropriate intervention will make any summative assessment judgments invalid as they would not reflect the practice of the student but of the teacher. Formative assessment should be an integral part of student practice involving feedback on knowledge and skills to enable students to move on safely. The assessment process will impact and possibly change the direction the students move within their practice.

It is also important to acknowledge that students' own culture and beliefs will influence their practice; they must also consider values and culture of those for whom they are developing a technological outcome. It is also important that the students consider likely possible impacts of any development work. Research and planning needs to be thorough and practiced if and 
where applicable. In the end not all students will succeed in producing a 'successful outcome'. This in itself is reflective of authentic practice.

\section{Conclusion}

This paper illustrates the need for teachers to have thorough knowledge of technological practice to plan and teach technology education. This is illustrated by a study showing how achievement levels of children improved when teachers planned a unit of work based as closely as possible on authentic technological practice. Development of an understanding of technological knowledge across four domains empowers teachers to plan and implement programmes that reflect authentic technological practice. It also allows them to plan formative assessment opportunities and give timely feedback to students which aid students' learning in technology education and ultimately alters their technological practice. 
Black, P., \& Wiliam, D. (1998). Inside the black box-raising standards through classroom assessment (1st ed.). London: King's College.

Brown, J., Collins, A., \& Duguid, P. (1989). Situated cognition and the culture of learning. Education Researcher, 18(1), 32-42.

Clarke, S., Hattie, J., \& Timperley, H. (2003). Unlocking formative assessment- practical strategies for enhancing learning in the primary and intermediate classroom (New Zealand edition ed.). Auckland: Hodder Moa Beckett.

Compton, V., \& Harwood , C. (1999). TEALS research project starting points and future directions. Paper presented at the Telecom Technology Education Conference, King's College, Auckland: 14-16 April.

Crooks, T., \& Flockton, L. (2001). Aspects of Technology Assessment Results 2000, 2001

Freeman, R. L. R. (1998). Planning and implementing assessment. London: Kogan Page Limited.

Gawith, J. (2000). Technology Practice: a structure for developing technological capability and knowledge in schools. Paper presented at the IDATER 2000, Loughborough University.

Hennessy, S. (1993). Situated cognition and cognition apprenticeship: implications for classroom learning. Studies in Science Education, 22, 1-41.

Hennessy, S., \& Murphy, P. (1999). The Potential for collaborative problem solving in design and technology. International Journal of Technology and Design Education, 9(1), 136.

Hill, A. M., \& Smith, H. A. (1998). Practice meets theory in technology education: A case of authentic learning in a high school setting. Journal of Technology, 9(2).

Jones, A., \& Moreland, J. (2001). Frameworks and cognitive tools for enhancing practicing teachers' pedagogical content knowledge. Sydney.

Kimbell, R. (1997). Assessing technology international trends in curriculum and assessment. Buckingham: Open University Press.

McCormick, R. (1997). Conceptual and procedural knowledge. International Journal of Technology and Design Education, 7, 141-159.

McGee, C., \& Fraser, D. (2001). The professional practice of teaching (second ed.). Palmerston North: The Dunmore Press.

Ministry of Education. (1995). Technology in the New Zealand Curriculum. Wellington: Learning Media.

Moreland, J., Jones, A., \& Chambers, M. (2001). Enhancing student learning in technology through teacher technological literacy. Wellington: University of Waikato. 
Pacey, A. (1983). The culture of technology. Oxford: Blackwell.

Rogoff, B. (1990). Apprenticeship in thinking: cognitive development in social context. New York: Oxford University Press.

Sutton, R. (1995). Assessment for learning. Salford: RS Publications.

Turnbull, W. (2002). The place of authenticity in technology in the New Zealand curriculum. International Journal of Technology and Design Education, 12, 23-40.

Wiggins, G. (1998). Educative assessment Designing assessment to inform and improve student performance. San Francisco: Jossey-Bass Inc. 